Rabaska

Revue d'ethnologie de l'Amérique française

DUbÉ, RICHARD. L'Univers de Ginet Leblond. Musée Place

Royale. Québec, s.é. 2008, 177 p. ISBN 978-2-98106-320-05

\title{
Yves Beauregard
}

Volume 9, 2011

URI : https://id.erudit.org/iderudit/1005921ar

DOI : https://doi.org/10.7202/1005921ar

Aller au sommaire du numéro

Éditeur(s)

Société québécoise d'ethnologie

ISSN

1703-7433 (imprimé)

1916-7350 (numérique)

Découvrir la revue

Citer ce compte rendu

Beauregard, Y. (2011). Compte rendu de [DUBÉ, RICHARD. L'Univers de Ginet

Leblond. Musée Place Royale. Québec, s.é. 2008, 177 p. ISBN 978-2-98106-320-05].

Rabaska, 9, 272-272. https://doi.org/10.7202/1005921ar

Ce document est protégé par la loi sur le droit d'auteur. L'utilisation des services d'Érudit (y compris la reproduction) est assujettie à sa politique d'utilisation que vous pouvez consulter en ligne.

https://apropos.erudit.org/fr/usagers/politique-dutilisation/
Cet article est diffusé et préservé par Érudit.

Érudit est un consortium interuniversitaire sans but lucratif composé de l’Université de Montréal, l’Université Laval et l’Université du Québec à Montréal. Il a pour mission la promotion et la valorisation de la recherche. https://www.erudit.org/fr/ 
Dubé, Richard. L'Univers de Ginet Leblond. Musée Place Royale. Québec, s.é. 2008, 177 p. ISBN 978-2-98106-320-05.

Ce somptueux ouvrage est le résultat de la collaboration de monsieur Richard Dubé, muséologue et ancien directeur des collections du Musée de la civilisation de Québec, du groupe de Communications de Science-Impact, de Jocelyne et Jean-Paul Trottier de la Galerie d'art Les Peintres Québécois inc. et surtout de l'artiste Ginet Leblond.

La parution de ce volume accompagne l'ouverture en 2008 du musée privé Place Royale situé au 40, rue Notre-Dame, à Québec. Propriété de Jean-Paul Trottier, ce nouveau musée est entièrement consacré à l'œuvre de l'artiste Ginet Leblond. Diplômée en arts plastiques de l'Université Laval, madame Leblond a aussi reçu une formation en dessin du Musée national des beaux-arts du Québec et elle a enseigné la peinture pendant une vingtaine d'années. Depuis trente ans, madame Leblond a créé plus de mille œuvres. Le nouveau musée qui lui est consacré présente sur trois étages une centaine d'œuvres parmi les plus représentatives de la production récente de l'artiste. Madame Leblond est peintre, sculpteur et céramiste. Cependant, ce que met en valeur le volume de Richard Dubé et le musée Place Royale ce sont ses meubles peints. Initiée aux antiquités québécoises par son conjoint MarcAndré Fortin, madame Leblond s'est mis à y dessiner et peindre des scènes de la vie traditionnelle du Québec des années 1880 à 1920. Coffres, armoires, bancs et panneaux de bois anciens, autant de supports où le lecteur et le visiteur pourront découvrir des scènes de fenaison, de promenades en carrioles, des artisans exerçant leurs métiers traditionnels, des lieux chargés d'histoire comme la Place Royale, le Château Frontenac, le Collège des jésuites, le Séminaire de Québec, le Monastère des ursulines, la terrasse Dufferin... Plus encore, les lecteurs et les visiteurs pourront y découvrir les splendeurs du fleuve Saint-Laurent, des moments de la vie urbaine et, aussi, le monde mystérieux des contes et légendes.

Lorsque l'on scrute les œuvres de madame Leblond, il n'est pas rare d'y retrouver les influences d'un Horatio Walker, d'un Clarence Gagnon, d'un Edmond J. Massicotte, du volume de Pierre-Georges Roy sur l'île d'Orléans, et même d'Adrien Hébert, d'Henri Julien, etc., autant d'artistes qui furent des témoins remarquables de la vie de nos devanciers.

Lancé en juillet 2008, L'Univers de Ginet Leblond, Musée Place Royale, présente une excellente sélection des œuvres de l'artiste, toutes accompagnées de textes fort riches en informations signés Richard Dubé. Complément indispensable à la visite du Musée Place Royale, ce volume peut aussi constituer un outil pédagogique formidable pour l'enseignement des us et coutumes d'autrefois au pays du Québec.

Yves BEAUREgard Québec 